\title{
Effect of hydrofluoric acid (HF) concentration to pores size diameter of silicon membrane
}

\author{
Norhafizah Burham $^{\mathrm{a}, \mathrm{b}, *}$, Azrul Azlan Hamzah ${ }^{\mathrm{a}}$ and Burhanuddin Yeop Majlis ${ }^{\mathrm{a}}$ \\ ${ }^{a}$ Institute of Microengineering and Nanoelectronics (IMEN), Universiti Kebangsaan Malaysia 43600 \\ Bangi, Selangor, Malaysia \\ ${ }^{b}$ Faculty of Electrical Engineering, Universiti Teknologi Mara (UiTM), 40450, Shah Alam, Selangor, \\ Malaysia
}

\begin{abstract}
This paper studies parameters which affect the pore size diameter of a silicon membrane. Electrochemical etching is performed in characterise the parameter involved in this process. The parameter has been studied is volume ratio of hydrofluoric acid (HF) and ethanol as an electrolyte aqueous for electrochemical etch. This electrolyte aqueous solution has been mixed between HF and ethanol with volume ratio 3:7, 5:5, 7:3 and 9:1. As a result, the higher volume of HF in this electrolyte gives the smallest pore size diameter compared to the lower volume of HF. These samples have been dipped into HF and ethanol electrolyte aqueous with supplied $25 \mathrm{~mA} / \mathrm{cm}^{2}$ current density for 20, 30, 40, and 50 minutes. The samples will inspect under Scanning Electron Microscope (SEM) to execute the pore formations on silicon membrane surface.
\end{abstract}

Keywords: Silicon membrane, volume ratio, hydrofluoric acid (HF), electrochemical etch, nanoporous

\section{Introduction}

Porous silicon is well known had an excellent chemical and physical stability which give better membrane performance with ordered pores compared to other organic and composite materials [1]. The porous silicon had a great deal in bio-separation that functions as a filter. This porous membrane also can be integrated with other component to make an entire system device.

In bioMEMS application, the porous filter can be used as a one component in MEMS lab-on-chip (LoC) system by integrating filter [2] with others control components such as micropump, microvalve and microneedles to make complete on-chip micro-total-analysis system ( $\mu$ TAS) [3]. Micro and Nano sieve biological fluids like blood cell, globular protein, virus and bacteria could separate through this nano pores sized [4]. Due to different size of biology components, porous membrane can be attached via different pore size diameter or multiple filtration process.

\footnotetext{
${ }^{*}$ Corresponding author: Norhafizah Burham, Institute of Microengineering and Nanoelectronics (IMEN), Universiti Kebangsaan Malaysia 43600 Bangi, Selangor, Malaysia. Tel.: +603-89118020; Fax: +603-89250439; E-mail: burhan@ukm.edu.my.
} 
The basic fabrication start with wet etching process to thin the silicon using a potassium hydroxide $(\mathrm{KOH})$, tetramethylammonium hydroxide (TMAH) or ethylene diamine and pyrocatechol (EDP). The next process is forming pores on silicon membrane surface. The pore can be formed using a different method that has been studied by other researchers like lithography and electrochemical etching process.

Several methods have been developed by other researchers to develop compatible porous membrane. Rijn et al. developed a silicon nitride micro sieve with pores size $3 \mu \mathrm{m}$ using MEMS fabrication techniques [5]. Next, the method was improved to produce smaller pores via laser interference lithography. Fissell et al. introduced monodispersed slit-shaped nanopores with width $9 \mathrm{~nm}$ for hemofiltration [6].

However, the simplest and economics will give an advantages. Striemer et al. has developed a simple method on fabricating nanopores silicon membrane. Rapid thermal annealing (RTA) process is used to get the pore size less than $100 \mathrm{~nm}$ on a silicon surface [7]. Another simplest method on fabricate micropores membrane are using electroplating and electrochemical etch [3].

The main issues on fabricating silicon membrane are to get the pore with nanosized range. So, the pore size diameter can be controlled with various factors. The first is doping type which can be categorized as a low doped, moderate doped and highly doped. For this various level doping characteristic are capable in forming a different pores size diameter. This level doping able to produce micropores, mesopores and macropores $[8,9]$ either using boron or phosphorus dopant.

This paper presents another factor that affect the pore size diameter which is HF concentration [10]. The process starts with $\mathrm{KOH}$ process to thin the un-doped silicon to get the silicon thickness $8.4 \mu \mathrm{m}$. Then proceed to electrochemical etch to form pores. The pore size diameter can be controlled during electrochemical etch process using different volume ratio between HF and ethanol. Finally, the analysis on producing the smallest and uniform pores can be applied to fabricate the filtration system for artificial kidney by modifying the surface on silicon to make it biocompatibility and anti-bio fouling.

\section{Fabrication process}

There are two processes involve for fabricate pores silicon membrane. The first part is fabrication of silicon membrane. Then proceed to electrochemical etching (ECE) to form pores on the silicon membrane surface. The details of fabrication process are discussed in this section.

\subsection{Silicon membrane fabrication}

The membranes were fabricated on $<100>400 \mu \mathrm{m}$ thick doubled-sided polished (DSP) silicon. The substrates were pre-coated on both sides with $200 \mathrm{~nm}$ thick silicon nitride. The substrates were patterned with a square dimension $750 \mu \mathrm{m} \times 750 \mu \mathrm{m}$ using $\mathrm{AZ} 4620$ positive photoresist on 1 inch square sample. After exposed under UV light for 80 seconds, the samples were developed using AZ 400K developer. The exposed layer nitride was removes by 4 hours etching in buffer oxide etch (BOE) solution. Next, the samples was dipped into $30 \% \mathrm{KOH}$ solution with constant temperature of $75^{\circ} \mathrm{C}$ for 9 hours to thin the bulk silicon until reached approximate $8 \mu \mathrm{m}$ thickness. The fabrication process was shown in Figure 1.

Figure 2(a) shows the top view of silicon membrane after $\mathrm{KOH}$ process. The sample was dipped in $30 \%$ Potassium Hydroxide $(\mathrm{KOH})$ with constant temperature set $70^{\circ} \mathrm{C}$. By repeating and controlling the process to get the silicon membrane $8.4 \mu \mathrm{m}$ thick. The $8.4 \mu \mathrm{m}$ thickness membrane was validated using Scanning Electron Micrograph (SEM) as shown in Figure 2(b). 


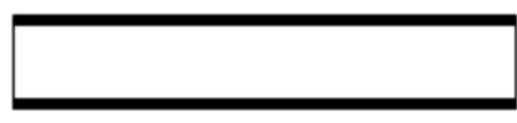

\section{Silicon Nitride 400 um}

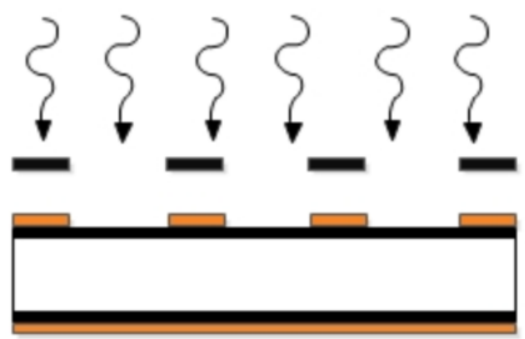

Expose using UV light

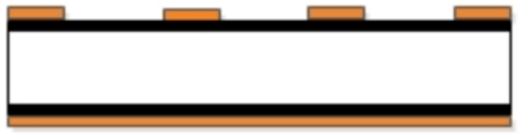

BOE process to remove nitride on unexposed surface

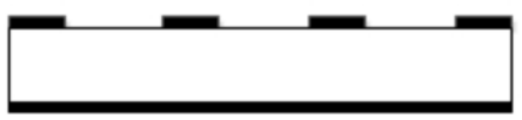

\section{Remove photoresist using Acetone}

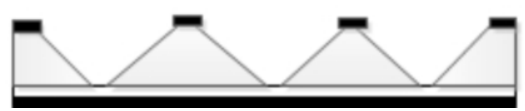

$\mathrm{KOH}$ process to get $8 \mathrm{um}$ thick membrane

Fig. 1. Silicon membrane fabrication process.

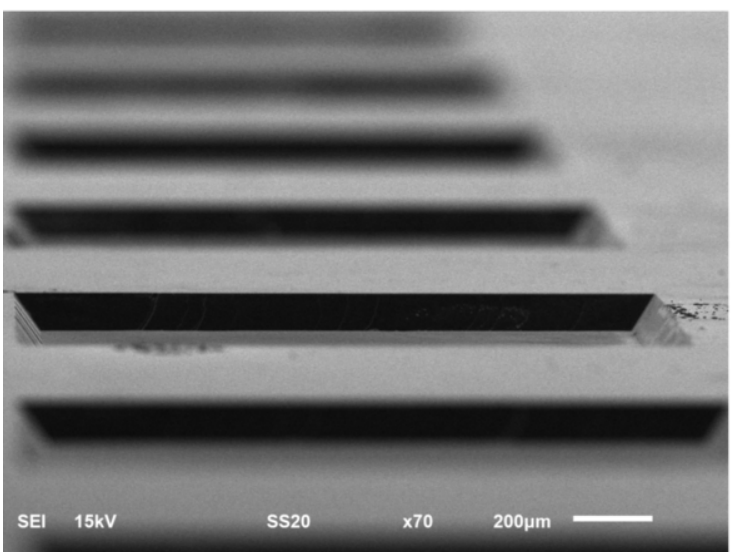

(a)

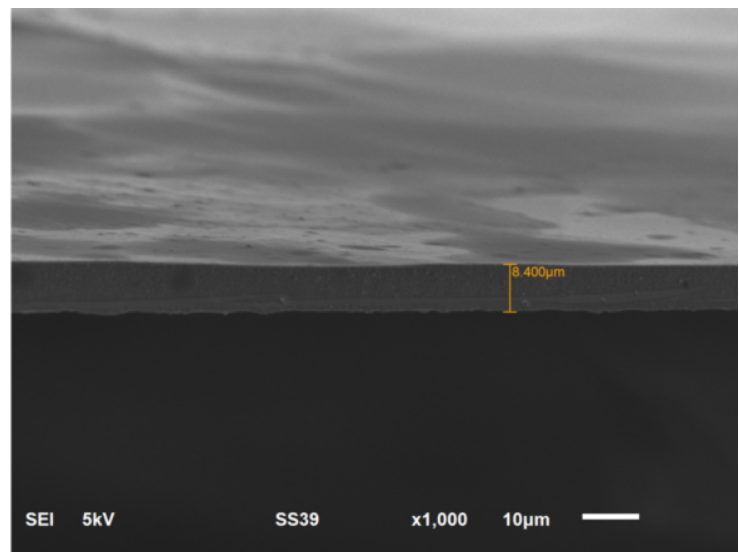

(b)

Fig. 2. (a) $750 \mu \mathrm{m} \times 750 \mu \mathrm{m}$ square frame after $\mathrm{KOH}$ process and (b) The $8 \mu \mathrm{m}$ thick silicon membrane after $\mathrm{KOH}$ process.

\subsection{Electrochemical etching setup}

Electrochemical etching was performed to form pores on silicon membrane surface using hydrofluoric acid (HF) solution [8]. The experiment setup was shown in Figure 3 by supplying a constant current between two electrodes immersed in Teflon cell containing an aqueous solution of $\mathrm{HF}$ and ethanol. Ethanol acts as the surfactant in reducing the hydrogen bubble throughout the process $[11,12]$. 
Fluorescence Light ( 30 Watt)
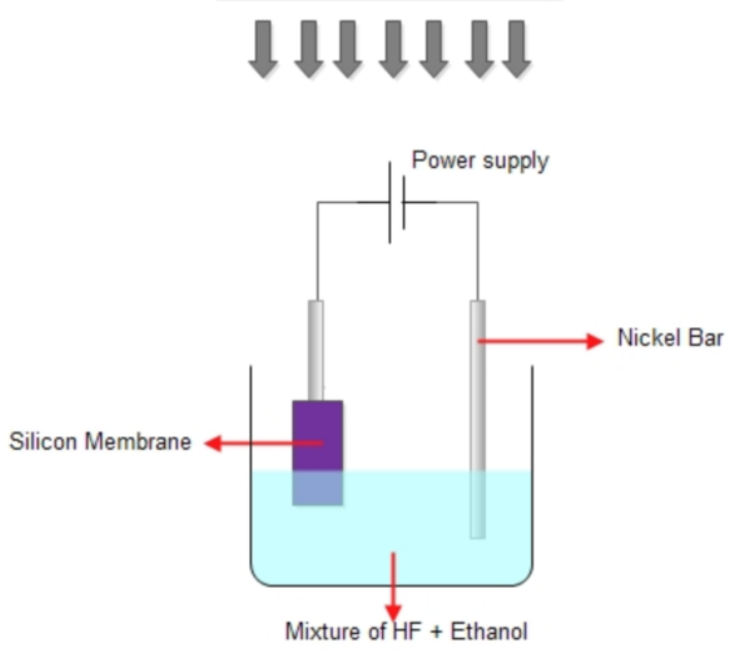

Fig. 3. Electrochemical etching experimental setup.

The current density has been set $25 \mathrm{~mA} / \mathrm{cm}^{2}$ for $20,30,40$, and 50 minutes. Finally, the samples were examined using Scanning Electron Microscope (SEM) precisely to verify the pore formation on silicon membrane.

A constant current is applied between the anode ( $\mathrm{Si}$ ) and the cathode (Nickel bar) immersed in electrochemical solution of hydrofluoric acid and ethanol with different volume ratio 3:7, 5:5, 7:3 and 9:1. The reaction of both electrodes takes place:

$$
\begin{aligned}
& N i: 2 H^{+}+2 e^{-} \rightarrow H_{2} \\
& S i: S i+6 F^{-}+2 H^{+}+2 e^{-} \rightarrow S i F_{6}{ }^{2-}+H_{2}
\end{aligned}
$$

The mechanism of pore formation starts with migration of electron and holes when applied electric field to attract charge carrier. The chemistry occurs on silicon surface involving competition between $\mathrm{Si}-\mathrm{O}, \mathrm{Si}-\mathrm{F}$ and $\mathrm{Si}-\mathrm{H}$ bond formation. So, when the concentration HF in electrolyte is low, oxidized silicon generate on the surface and can attack rapidly by $\mathrm{F}^{-}$and make the water molecules to take over the role of nucleophile. So, the lack of $\mathrm{F}$ ion make the oxide cannot be removed from the silicon surface. It is because the insulated oxide terminates pores propagation [13].

\section{Result and discussion}

The pores structure on silicon membrane surface was inspected under SEM to validate the pore size diameter and structure. Figure 4 shows the pore structure on silicon membrane surface after electrochemical etching process. The current density set is $25 \mathrm{~mA} / \mathrm{cm}^{2}$ for 20 minutes with different $\mathrm{HF}$ and ethanol volume ratio in electrolyte aqueous solution which is 3:7, 5:5, 7:3 and 9:1. 


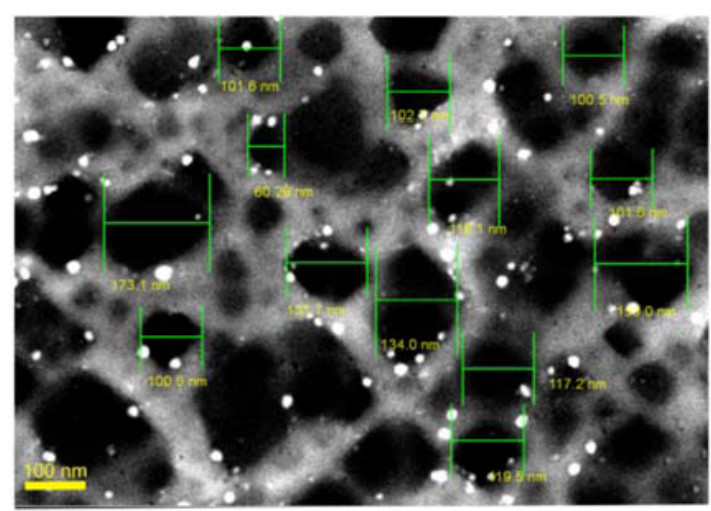

a) $3: 7$

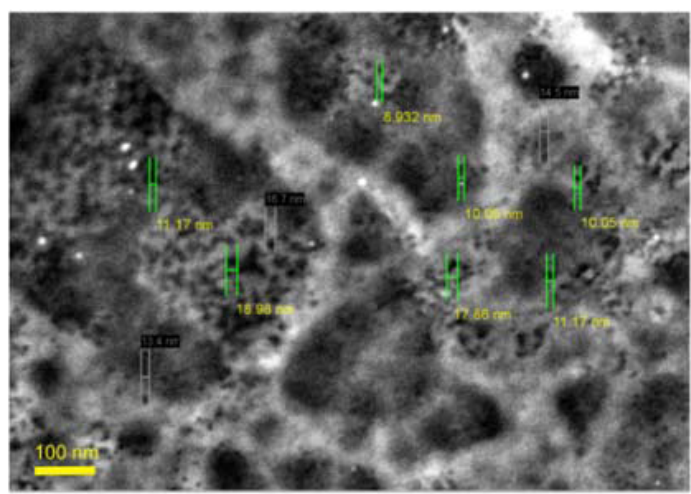

c) $7: 3$

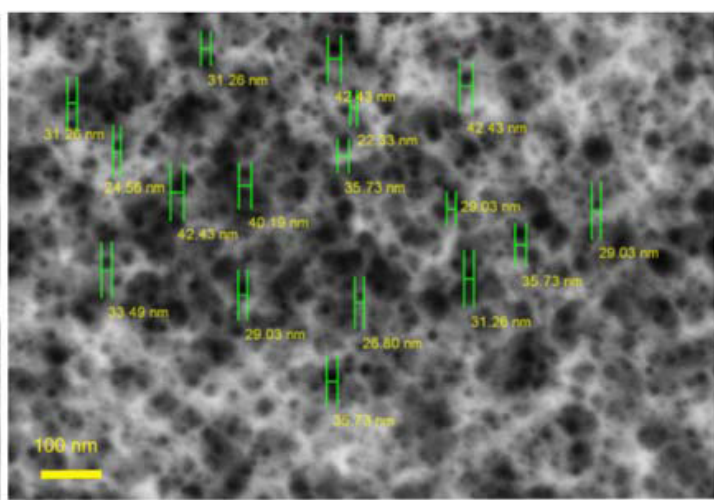

b) $5: 5$

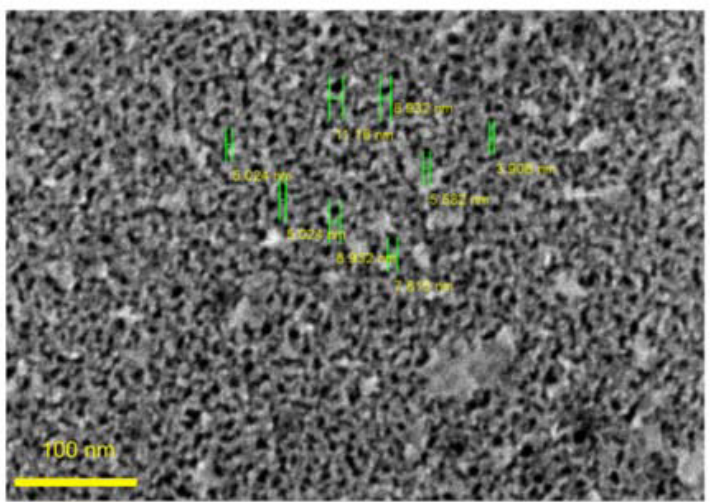

d) $9: 1$

Fig. 4. The pore structure different volume ratio HF: Ethanol.

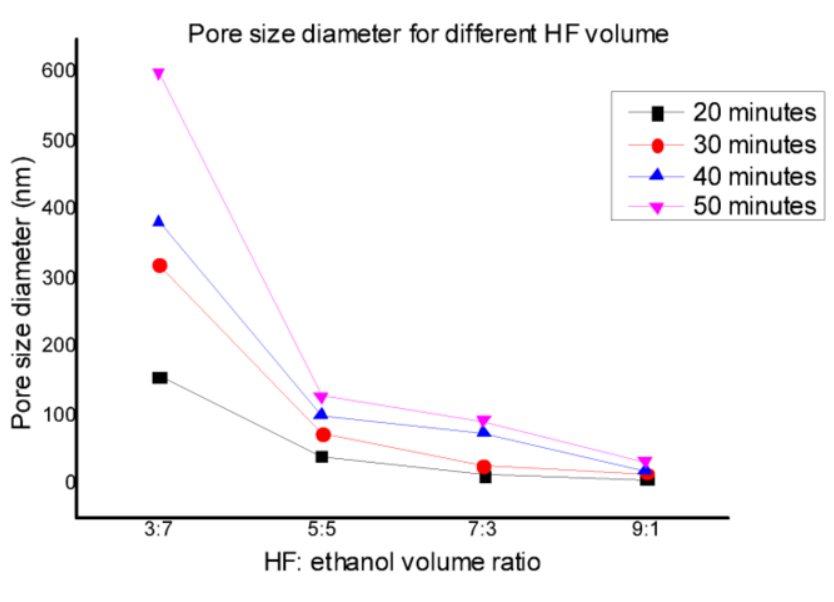

Fig. 5 (a) Pore size diameter for different HF and ethanol volume ratio for variation time.

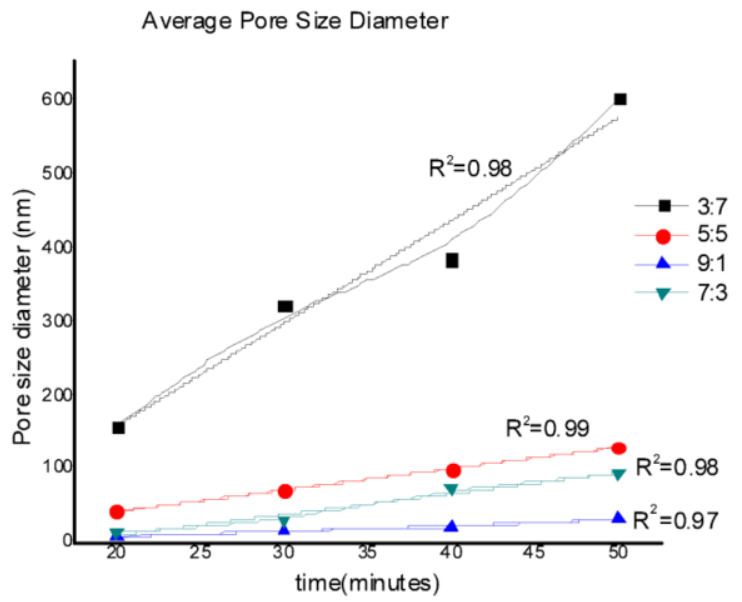

Fig. 5 (b) The average pore diameter in different HF ethanol volume ratio. 
Table 1

The range of pore size diameter with different volume ratio of HF and ethanol

\begin{tabular}{lllll}
\hline $\begin{array}{l}\text { Time } \\
\text { (minutes) }\end{array}$ & $\begin{array}{l}\text { Pore diameter } \\
3: 7\end{array}$ & $5: 5$ & $7: 3$ & $9: 1$ \\
\hline 20 & $60 \mathrm{~nm}-200 \mathrm{~nm}$ & $30 \mathrm{~nm}-50 \mathrm{~nm}$ & $9 \mathrm{~nm}-19 \mathrm{~nm}$ & $5 \mathrm{~nm}-10 \mathrm{~nm}$ \\
& & & \\
30 & $220 \mathrm{~nm}-360 \mathrm{~nm}$ & $40 \mathrm{~nm}-100 \mathrm{~nm}$ & $16 \mathrm{~nm}-34 \mathrm{~nm}$ & $13 \mathrm{~nm}-25 \mathrm{~nm}$ \\
40 & $200 \mathrm{~nm}-500 \mathrm{~nm}$ & $50 \mathrm{~nm}-150 \mathrm{~nm}$ & $57 \mathrm{~nm}-101 \mathrm{~nm}$ & $17 \mathrm{~nm}-30 \mathrm{~nm}$ \\
50 & $600 \mathrm{~nm}-1 \mu \mathrm{m}$ & $50 \mathrm{~nm}-300 \mathrm{~nm}$ & $58 \mathrm{~nm}-120 \mathrm{~nm}$ & $30 \mathrm{~nm}-50 \mathrm{~nm}$ \\
\hline
\end{tabular}

In Figure 5(a) shows the graph between HF concentration and pore size diameter. The HF quantity effect the pore size diameter of silicon membrane during electrochemical etching. From the graph shows the low HF quantities produce the wide pores. Based on kidney filtration system, there are three membrane involved with the pore size diameter range from $6 \mathrm{~nm}$ up to $100 \mathrm{~nm}$ [14]. This conventional electrochemical etching process is capable to produce the pores with size less than $100 \mathrm{~nm}$ by controlling certain parameter.

In Figure 5(b) shows the graph of average pore diameter with different HF volume and immersed time during electrochemical etch. The average pores are counted by picking 20 samples of pores. The smallest pore shows in aqueous solution 9:1 between HF and ethanol. The pore size diameter increase according to immersed time in electrolyte aqueous with $25 \mathrm{~mA} / \mathrm{cm}^{2}$ current density applied.

The range of pore diameter size was measured under SEM shows in Table 1. The size of pores was measured to study the effect of volume ratio of HF and ethanol while performing electrochemical etches process. As the result shown, the HF amount takes a principal role in forming nanosized pores. The higher HF amount forms the smallest pores on silicon membrane surface.

Zhang and $\mathrm{H}$. Foll et al. state that the highest HF concentration increases the pore tip current density and also reduces the thickness of the space-charge layer. So, smaller pores and thicker wall is formed. On the other hand, the native silicon oxides will growth on silicon surface. The HF aqueous solution used to polish the silicon to remove the native oxide. This native oxide has been dissolved by HF through the complex fluoride formation in the solution. The dissolution silicon oxide rate increase by increasing the HF volume, which automatically increase the critical current density at the covered oxide on silicon. As a result, the pores structure become small and the pore walls become thick by increasing the HF concentration $[15,16]$.

The other factor affect pore size diameter on the membrane surface is immersed time for electrochemical etching process. As shown in Table 1, the longest time make the pore diameter wider. But this parameter is not suitable in forming a uniform pores because the pore size and structure difficult to control. By comparing immersed time for 20 and 50 minutes shows that at 20 minutes the pore structure are uniform compared to the 50 minutes for each variation HF quantity.

\section{Conclusion}

Porous silicon membrane successfully fabricates initially using $\mathrm{KOH}$ etching followed by electrochemical etching. The sample initially etched in $30 \% \mathrm{KOH}$ solution at $75^{\circ} \mathrm{C}$ for 9 hours to remove silicon to get $8.4 \mu \mathrm{m}$ silicon thick. The pores have been created using electrochemical etching with different HF and ethanol volume ratio and time immersed in electrolyte aqueous solution to study the pore size diameter on the silicon surface. The smallest pores can be formed in aqueous solution 9:1 of 
$\mathrm{HF}$ and ethanol with the pore size diameter $5 \mathrm{~nm}$ to $10 \mathrm{~nm}$. Indirectly, by manipulating the electrochemical etch time shows the pore size diameter become larger. Due to this reliable, economical and simplest method can study two parameters in characterize the pore size diameter. This nanofilter can be fabricated and integrated to produce an artificial kidney filtration system in the future.

\section{References}

[1] S.P. Adiga, C. Jin, L.A. Curtiss, N.A. Monteiro-Riviere and R.J. Narayan, Nanoporous membranes for medical and biological applications, Wiley Interdisciplinary Reviews: Nanomedicine and Nanobiotechnology 1 (2009), 568-581.

[2] W.L.Y.C.D.C. Liu, Filter based receive-side spatial compounding for veterinary ultrasound B-mode imaging, BioMedical Materials and Engineering 24 (2013), 1193-1199.

[3] A.A. Hamzah, H.E.Z. Abidin, B.Y. Majlis, M.M. Nor, A. Ismardi, G. Sugandi, T.Y. Tiong, C.F. Dee and J. Yunas, Electrochemically deposited and etched membranes with precisely sized micropores for biological fluids microfiltration, Journal of Micromechanicsl Microengineering 23 (2013), 836-840.

[4] D.T.D. Kim, The effect of counter-ions on the ion selectivity of potassium and sodium ions in nanopores, Bio-Medical Materials and Engineering 24 (2013), 373-382.

[5] H.V.J.H.D. Tong, V.J. Gadgil, C.G. Bostan, C.J.M.v.R.E. Berenschot and M. Elwenspoek, Silicon nitride nanosieve membrane, Nano Letters 4 (2004), 283-287.

[6] A.D.W.H. Fissell, A.N. Eldridgeb, A.J. Fleischman and S.R.A.L. Zydneyc, High-performance silicon nanopore hemofiltration membranes, Journal of Membrane Science 326 (2009), 58-63.

[7] T.R.G.C.C. Striemer, J.L. McGrath and P.M. Fauchet, Charge-and size-based separation of macromolecules using ultrathin silicon membranes, Nature Publishing Group 445 (2007), 749-753.

[8] V. Lehmann, Electrochemistry of Silicon: Instrumentation, Science, Materials and Applications, WileyVCH, Verlag GmbH, New Jersey, 2002.

[9] A.G.N.DN. Pagonis, Free-standing macroporous silicon membranes over a large cavity for filtering and lab-on-chip applications, Microelectronic Engineering 83 (2006), 1421-1425.

[10] P.L.P. Kumar, M. Ghosh, F. Ludwig and A.M. Schilling, Effect of HF concentration on physical and electronic properties of electrochemically formed nanoporous silicon, Journal of Nanomaterials 2009 (2009). doi: 10.1155/2009/728957

[11] J. Salonen and V.P. Lehto, Fabrication and chemical surface modification of mesoporous silicon for biomedical applications, Chemical Engineering Journal 137 (2008), 162-172.

[12] T. Dittrich, S. Rauscher, V.Y. Timoshenko, J. Rappich, I. Sieber, H. Flietner and H.J. Lewerenz, Ultrathin luminescent nanoporous silicon on n-Si: pH dependent preparation in aqueous NH4F solutions, Applied Physics Letters 67 (1995), 1134-1136.

[13] M.J. Sailor, Fundamentals of porous silicon preparation, in: Porous Silicon in Practice: Preparation, Characterization and Applications, Wiley-VCH, Verlag GmbH \& Co. KGaA, New Jersey, 2012, pp. 1-42.

[14] B.D.G.J. Tortora, Principles of Anatomy and Physiology, John Wiley \& Sons Inc., New Jersey, 2006.

[15] X.G. Zhang, Morphology and formation mechanisms of porous silicon, Journal of the Electrochemical Society $\mathbf{1 5 1}$ (2004), 69-80.

[16] H. Föll, J.C. and S. Frey, Porous and nanoporous semiconductors and emerging applications, Journal of Nanomaterials 2006 (2006), 1-10. 